\title{
Sepse, um problema do tamanho do Brasil
}

\author{
Sepsis, a problem with the size of Brazil
}

S epse é a principal causa de mortalidade em unidades de terapia intensiva não-cardiológicas em todo mundo, especialmente em decorrência de disfunção de múltiplos órgãos. Estima-se uma taxa de mortalidade média de $40 \%$. Cerca de $10 \%$ dos leitos destas unidades são, atualmente, ocupados por pacientes sépticos. Do ponto de vista populacional, cerca de 18 milhões de novos casos de sepse grave serão diagnosticados a cada ano em todo mundo, com crescimento estimado de $1 \%$ ao ano. Só nos Estados Unidos, poderemos ter, em poucos anos, cerca de 1 milhão de casos novos de sepse grave a cada ano.

Estes números foram apresentados às comunidades leiga e científica somente nos últimos anos. Neste período vários estudos epidemiológicos têm sido publicados na literatura médica oriundos de diferentes países. $O$ crescente interesse pelo tema tem mudado o perfil de atuação de pesquisadores, profissionais e gestores de saúde e órgãos governamentais. Não mais encarada como uma complicação eventual, sepse direciona as atenções destes profissionais no sentido de reduzir sua incidência e taxa de mortalidade. Dentre as diversas iniciativas, a mais ambiciosa é a Surviving Sepsis Campaign (Campanha Sobrevivendo à Sepse), cujo objetivo é reduzir a mortalidade em $25 \%$ do risco relativo de morte em 5 anos $^{1}$. Implementada em vários países, incluindo Brasil, a Campanha vem mobilizando esforços em diferentes instituições e começa a envolver setores da saúde pública.

Nesta edição da Revista Brasileira de Terapia Intensiva, Sales Jr e col. ${ }^{2}$ apresentam dados sobre a epidemiologia da sepse que corroboram com os já mencionados neste editorial. Os autores avaliaram, em 65 unidades de terapia intensiva brasileiras, mais de 3.000 pacientes dos quais $16 \%$ apresentaram sepse, em algum momento da internação. A taxa de mortalidade variou de $16 \%$ para aqueles pacientes sem disfunções orgânicas a $65 \%$ nos pacientes com choque séptico. Além disso, relataram que a principal fonte de infecção do quadro séptico foi a pulmonar e que, entre as culturas positivas, houve predomínio de bactérias gram-negativas.
O único estudo epidemiológico brasileiro ${ }^{3}$ que serve de comparação a estes dados foi publicado há dois anos, mostrou dados bastante semelhantes no que diz respeito à taxa de ocorrência e de mortalidade e perfis bacteriológicos. Adicionalmente, ao buscarmos dados internacionais, o presente estudo mostra que o Brasil apresenta taxa de ocorrência superior a muitos estudos epidemiológicos realizados em outros países, corroborando a tese da "incidência tratada"4. Segundo este conceito, países em que há pouca disponibilidade de leitos de terapia intensiva relativa à demanda, políticas institucionais favorecem a admissão de pacientes sépticos, o que aumentaria a taxa de ocorrência ou a densidade de incidência. Em recente revisão, Angus e col. ${ }^{5}$ mostraram que o Brasil e o Reino Unido são os países que apresentam maior taxa de ocorrência de sepse em unidades de terapia intensiva e possuem semelhantes políticas de admissão e alta nestas unidades. Por fim, o presente estudo ressalta a importância da infecção respiratória como origem do quadro séptico e o predomínio de bactérias gram- negativas em culturas positivas de pacientes sépticos independentemente da origem da infecção. Estes dados estão de acordo com boa parte dos estudos publicados. Especificamente quanto ao predomínio de gram-negativos esta é uma constatação em estudos realizados exclusivamente em terapia intensiva, mas estudos populacionais apontam para um predomínio de gram-positivos nos últimos anos quando se considera pacientes admitidos com sepse em instituições hospitalares ${ }^{6}$.

Indubitavelmente, este estudo acresce, sobremaneira, nosso entendimento epidemiológico de sepse em nosso país. Reforça que o foco de todos aqueles envolvidos, direta ou indiretamente com o problema, deve ser a prevenção e a redução de mortalidade de sepse através da implementação de intervenções precoces guiada por protocolos gerenciados em nossas instituições. Este estudo servirá ainda como fonte de consulta periódica para termos uma estimativa do impacto da Campanha Sobrevivendo à Sepse que ora se desenvolve em nosso país.

Eliézer Silva 


\section{REFERÊNCIAS}

01. Dellinger RP, Carlet JM, Masur H et al - Surviving Sepsis Campaign Management Guidelines Committee. Surviving Sepsis Campaign guidelines for management of severe sepsis and septic shock. : Crit Care Med, 2004;32:858-873.

02. Sales Júnior JAL, David CM et al - RBTI - Revista Brasileira Terapia Intensiva, 2006;18(1):9-17

03. Silva E, Pedro Mde A, Sogayar AC et al - Brazilian Sepsis Epidemio- logical Study. Brazilian Sepsis Epidemiological Study (BASES study). Crit Care, 2004;8:R251-R26060.

04. Linde-Zwirble WT, Angus DC - Severe sepsis epidemiology: sampling, selection, and society. Crit Care, 2004;8:222-226.

05. Angus DC, Pereira CAP, Silva E - Epidemiology of severe sepsis around the world. Endocrine, Metabolic \& Immune Disorders - Drug Targets, 2006;6:7-16.

06. Martin GS, Mannino DM, Eaton S et al - The epidemiology of sepsis in the United States from 1979 through 2000. N Engl J Med, 2003;348:1546-1554 